\title{
Três Obstáculos Epistemológicos Para o Reconhecimento da Subjetividade na Psicologia Clínica
}

\author{
Maurício S. Neubern ${ }^{1}$ \\ Universidade de Brasilia
}

\begin{abstract}
Resumo
No presente artigo, obstáculos epistemológicos são concebidos como formas de construção do pensamento presentes na psicologia clínica que não integram a complexidade e as diversas condições dos processos subjetivos. Parte-se de uma breve contextualização do percurso do tema da subjetividade na ciência e na psicologia: de um espaço marginal, quando é vista como oposição à objetividade, a uma posição privilegiada em que é discutida como momento integrante da construção do saber. Contudo, neste momento a psicologia clínica se depara com grandes dificuldades, pois as influências recebidas do paradigma dominante são pouco condizentes com a abordagem da subjetividade. Os obstáculos epistemológicos - como o conhecimento geral e totalitário, as tendências patologizantes e as conclusões apressadas - são momentos de tais influências que descaracterizam a subjetividade como objeto de estudo e, em conseqüência, opõem-se às exigências necessárias para a abordagem das mesmas. Sendo assim, buscam-se destacar suas principais características e possibilidades de superação de modo que sua retificação aponte novos caminhos para a implantação de uma forma de pensar e investigar coerentes com as condições da subjetividade.

Palavras-chave: Obstáculos epistemológicos; epistemologia; subjetividade; psicologia clínica.
\end{abstract}

\section{Three Epistemological Obstacles to the Recognizing of Subjectivity in Clinical Psychology}

\begin{abstract}
In this article, epistemological obstacles are understood as a kind of though construction that does not integrate the complexity and the different conditions of the subjective process. The text begins with an introduction about the trajectory of subjectivity in both science and psychology. First, the subjectivity occupied a marginal place and it was seen as the oposite of objectivity; afterwards it became a central question, when it was reconized as an important moment to the construction of the knowledge. However, nowadays, clinical psychology faces huge difficulties, caused by the influences received from the dominant paradigm that are not coherent with the approach from the subjectivity. The epistemological obstacles - general and totalitarian knowledge, trends toward patologization and hurried conclusions - are examples of the influences that make subjectivity loose its potential as object of study, and, consequently, are opposed to the demands of this approach. This article seeks to show the main features of those obstacles and the possibilities of correction so as to suggest more coherents ways of thinking about and developing research on subjectivity.

Keywords: Epistemological obstacles; epistemology; subjectivity; clinical psychology.
\end{abstract}

\section{O Problema da Subjetividade na Psicologia Clínica}

O presente texto consiste em uma reflexão crítica sobre a contextualização da subjetividade na psicologia clínica. Por subjetividade busca-se um conceito complexo do psíquico que abranja suas múltiplas dimensões sem lhe impor mutilações ou reduções, de modo a possibilitar um estudo científico do sujeito no cotidiano. Gonzalez Rey (1997) a define como a constituição psíquica do sujeito individual que integra processos e estados do mesmo em cada um de seus momentos de ação social, momentos estes que implicam em sentidos subjetivos. Ao mesmo

\footnotetext{
1 Endereço para correspondência: SQS 411, bl C, apt 101, 70277-030, Brasília, DF. Fone (61) 346-4838. E-mail: mneubern@solar.com.br
}

tempo, expressa-se como constituinte da vida social - a subjetividade social - que se diferencia da individual por seu cenário de constituição.

Segue-se um percurso em que a subjetividade é marginalizada do processo científico, momento em que é concebida como oposição à objetividade, e, em seguida, é discutida como condição integrante da construção do saber científico. Nesse ponto, a psicologia se depara com grande desafio, pois ao mesmo tempo em que são abertos novos campos de investigação, seja quanto à construção de objetos de estudo, seja quanto à construção da ciência, ela se vê presa em suas limitações epistemológicas que tradicionalmente favoreceram a exclusão da subjetividade. Em outras palavras, enquanto na revolução atual de paradigma (Morin, 1998; Santos, 1989) surgem novas possibilidades de qualificação da subjetividade, boa parte 
das escolas e ramos dominantes da psicologia ainda se mantêm presos a cosmovisões onde ela é marginalizada e concebida como um risco ao procedimento objetivo.

Embora tal influência tenha ocorrido em todos os ramos da psicologia, deve-se ressaltar que a escolha da clínica para a discussão do tema não ocorre apenas devido à formação do autor. A natureza do trabalho clínico levou a uma contradição interessante pois permitiu, por um lado, a criação de conceitos e abordagens como alternativas interessantes para a subjetividade, mas ao mesmo tempo situou-se como empresa indigna da confiabilidade científica. Entende-se que, provavelmente, tal aspecto tenha contribuído para intensificar a exclusão da subjetividade na clínica, como para implantar concepções pouco condizentes com o espírito científico, como os obstáculos epistemológicos (Bachelard, 1985, 1996). Sendo assim, pretende-se destacar no texto que, dentre as inúmeras necessidades de reformulações epistemológicas para o reconhecimento da subjetividade, deve-se discutir, sob certos parâmetros, as características e possibilidades de superação desses obstáculos epistemológicos. Sua retificação pode apontar caminhos não apenas para um estudo científico da subjetividade, mas também posteriormente para uma forma de pensar científica na psicologia condizente com o estudo da mesma. Nesse sentido, a reflexão presente na clínica pode contribuir significativamente para a psicologia enquanto ciência.

\section{O Percurso da Subjetividade na Psicologia: de Marginal a Desafio}

\section{A Subjetividade Como Processo Marginal na Ciência}

Uma das primeiras questões presentes na reflexão epistemológica da atualidade é a relação entre a condição absolutista que a ciência ocupou no cenário das sociedades ocidentais e a cegueira sistemática que ela mesma desenvolveu sobre as possibilidades de análise de suas condições de surgimento. Por um lado, a empresa científica é erigida em torno da pretensão de um conhecimento confiável e comprometido com o ideal da verdade. Seu arcabouço lhe permitia desvendar as aparências dos fenômenos, atingindo à realidades unívocas e universais que, uma vez conhecidas, possibilitavam a predição e o controle de tais fenômenos. Os dois últimos séculos assistiram, portanto, a um desenvolvimento tecnológico assombroso e a um controle da natureza nunca antes imaginado.

No entanto, esse compromisso fervoroso com as luzes, que em seus momentos mais característicos opunham-se sistematicamente à ignorância do saber comum (Santos, 1987, 1989), desvinculou-se dos processos históricos e sócio-culturais presentes na construção da ciência. Uma vez que era possível decifrar o segredo de como as coisas realmente são, para o pensamento científico não fazia sentido algum indagar sobre as demais questões implicadas, como as históricas (como vieram a ser), culturais (que bases existem de crenças e linguagem para que fossem), sociais (como as comunidades decidiram para que fosse), dentre outras. Mais que isso, era preciso que tais dimensões fossem vistas como exteriores à construção científica, pois a assepsia conceitual e metodológica era uma condição necessária para seu sucesso.

Nesse sentido, a subjetividade humana foi submetida a um duplo processo de exclusão, ora como momento da construção do saber, ora como objeto de estudo. Isso é compreensível dentro do ponto de vista científico, posto que o entrelaçamento de sentidos e significados, necessariamente históricos e contextuais, bem como seus diversos momentos irregulares e irreversíveis promoveram a subjetividade como uma ameaça efetiva contra as pretensões de um saber calcado numa cosmovisão onde a realidade é ordenada, estática e ahistórica e a metodologia deveria buscar condições para que tais características do real fossem retratadas fielmente e sem interferências (Gonzalez Rey, 1996). Logo, no que se refere às condições presentes na construção da ciência, a subjetividade torna-se proscrita, passando a nunca ter reconhecida sua participação, mesmo que presente no seio das mais importantes descobertas. Por outro lado, enquanto objeto de estudo, tornou-se igualmente excluída, pois as múltiplas disjunções e reduções que lhe submeteram para enquadrá-la na vulgata científica descaracterizaram-na por completo. Processos essencialmente subjetivos como as emoções passam a ser concebidos por noções altamente incoerentes com suas condições: em alguns momentos são alçados ao universalismo que se sobrepõe ao singular; em outros são absorvidos nas relações neurológicas ou nas construções da linguagem; em outros ainda são subjugados a um isomorfismo arbitrário dos procedimentos estatísticos. Desconsiderou-se, quase por completo, sua condição subjetiva que implica numa articulação com os demais processos envolvidos sem se esgotar em nenhum deles e nas qualidades complexas emergentes dessas relações (Gonzalez Rey, 1997; Neubern, 1999).

No que se refere à psicologia, tal problemática foi caracterizada por marcantes contradições, principalmente devido ao lugar que tal ciência veio a ocupar na grande divisão do paradigma ocidental. Segundo alguns autores (Morin, 1998; Santos, 1987), com o Cogito de Descartes 
possibilitou-se efetivar uma separação que foi determinante para o conhecimento no ocidente, sendo que, de um lado da divisão, encontrava-se a ciência com sua linguagem técnica e prosaica, com seu arsenal estatístico e lógico e os princípios isomórficos de conhecimento do real. Sob a égide da física, o estudo dos fenômenos naturais deveria ocorrer livre de quaisquer influências infundadas: só seria possível o estudo confiável de fenômenos como as reações químicas, os astros, e o corpo humano se ciências como a química, a astronomia e a medicina se divorciassem em definitivo de suas parceiras alquimia, astrologia e, no caso da medicina, de noções como fluídos e éters. Do outro lado da divisão, encontravam-se disciplinas como a filosofia, o direito, a teologia, as artes e um dos inimigos maiores do pensamento científico - o senso comum. De modo semelhante, neste outro lado tornava-se possível o conhecimento sobre o destino do homem, suas relações com o mundo, Deus, os deveres, a sociedade, dentre outros, numa linguagem com múltiplos meios de expressão, como a poesia, mas indigna de confiabilidade.

A psicologia, como boa parte das ciências sociais, nasce em meio a um considerável conflito, como se buscasse transpor as distâncias do abismo criado pelo paradigma dominante. Um de seus principais objetivos era o de se firmar enquanto conhecimento científico, o que perpassou de diferentes modos o surgimento da maior parte de suas escolas e áreas. Mesmo em escolas como a psicanálise, que promoveu importantes rupturas com a cosmovisão dominante (como no caso do resgate da constituição histórica) ou das escolas humanistas, que criticaram severamente as pretensões de controle, a influência do paradigma esteve presente no compromisso, explícito ou não, de um conhecimento confiável, distinto dos demais presentes no outro lado da divisão. Por outro lado, ao se propor ao estudo do humano (seja suas funções mentais, seu comportamento, seu psiquismo) ela buscará abordar problemáticas presentes do outro lado do abismo que se constituía como reino do subjetivo e da qualidade, cujos processos eram altamente incoerentes com a confiabilidade preconizada na ciência. Dentre as inúmeras conseqüências que isso acarretou para a psicologia, uma teve relevância especial para sua inferioridade diante das ciências "duras": sua multiplicidade, manifesta por meio de numerosas escolas de pensamento, parece ter se constituído como uma afronta ao pressuposto da verdade única.

Ao mesmo tempo, suas possibilidades de investigação foram cada vez mais constrangidas em nome das exigências científicas, pois além das múltiplas simplificações que impôs a seus objetos de estudo, ela se viu impelida ao silêncio em outro campo fundamental do saber - a subjetividade presente em sua construção. É provável que a psicologia tenha sido uma das ciências que sofreram maior impacto de descaracterização diante do paradigma dominante, pois se propunha a investigar o psiquismo do próprio criador da maravilhosa empresa científica. Ao mesmo tempo em que esse homem era alçado a senhor da natureza, capaz de controlar e prever seus movimentos, ele jamais poderia ser tomado integralmente como objeto de estudo, pois seus processos subjetivos eram essencialmente subversivos e inadequados para condições confiáveis de pesquisa. Nessa perspectiva, a cegueira dos sistemas de conhecimento quanto a suas origens e condições apresentava interessante similaridade com a interdição do auto-conhecimento do sujeito cientista, no sentido de um reconhecimento efetivo dessa condição como momento fundamental da construção da ciência.

\section{Novas Possibilidades Para o Reconhecimento da Subjetividade na Ciência e Psicologia}

No entanto, a partir da reflexão epistemológica presente no atual século, abriu-se um vasto campo de investigação sobre as origens e cenários do conhecimento científico $^{2}$. Tal reflexão inicia-se basicamente por um questionamento incisivo contra a dogmatização científica, e nesse ponto Bachelard (1985; 1996) é um de seus maiores marcos, e culmina com uma discussão mais abrangente sobre as complexas condições que o abarcam. Dito de outro modo, a reflexão passou a abranger não só os pressupostos que o fundamentavam, mas também as várias facetas sócio-culturais envolvidas com o mesmo. É nesse sentido que Morin (1983), discorrendo sobre as condições da ciência, aponta que além de uma relação com a realidade (por meio de um arsenal de conceitos, técnicas e instrumentos) deve-se considerar também uma gama considerável de momentos da comunidade científica (como os consensos e as rivalidades), permeados por múltiplas dimensões fundamentais para a determinação da objetividade. Em outras palavras, o autor aponta para uma estreita relação entre o elemento fundador e validador da verdade fundacional da ciência (a objetividade) e as próprias condições intersubjetivas presentes em sua construção, com as quais passa a desempenhar uma relação paradoxal de autonomia e dependência. Sob outro ponto de vista, as reflexões de

\footnotetext{
${ }^{2}$ Logicamente, tais reflexões relacionam-se não só com as condições sócio-culturais, mas também com as próprias necessidades e descobertas científicas e filosóficas da atualidade. Muitas dessas necessidades denunciavam abertamente as limitações do paradigma dominante.
} 
Kuhn (1996) parecem trazer contribuições semelhantes, principalmente no tocante ao comum das comunidades em suas relações com o paradigma (a estrutura da comunidade, a constelação dos compromissos dos grupos e os exemplos compartilhados).

A pós-modernidade, a seu turno, traz reflexões de grande interesse para tais questões, em que a dimensão da linguagem ocupa um lugar central para a compreensão do subjetivo ${ }^{3}$ na construção do saber científico. Segundo Lyotard (1979), deve-se buscar compreender a ciência numa perspectiva de jogos de linguagem onde as regras sejam conhecidas e partilhadas pelos participantes. A discussão sobre a prova da prova, isto é, a discussão sobre os postulados axiomáticos não consistiria em um demérito para a ciência, uma vez que ela consiste em uma narrativa cujos resultados dizem respeito especificamente à seus jogos de linguagem e não a uma verdade transcendente. Contudo, a própria interação entre as múltiplas narrativas do cenário social traz uma implicação marcante para a ciência quanto à suas relações com o mundo social. A técnica, que permite maior eficiência da prova, não é regida por um critério de verdade, mas de performance, em que um maior out put (informações ou modificações obtidas) é exigido em função de um in put (dispêndio de energia) cada vez menor. Desse modo, num cenário capitalista, cria-se um elo recursivo entre técnica e riqueza, o que contribuirá para o crescimento progressivo de ambas. Ao mesmo tempo, a performance passa a ocupar um papel fundamental para a verdade (própria da narrativa científica, num jogo de linguagem denotativo) e para a justiça (em seu jogo prescritivo). Sendo assim, o pensamento pós-moderno traz uma visão com multiplicidade de saberes narrativos com pertinências específicas, ao invés da busca obsessiva da verdade única por métodos confiáveis. Ao mesmo tempo, aponta para relações importantes entre os jogos de linguagem presentes nessas narrativas.

Pode-se afirmar que na psicologia a influência pósmoderna se faz basicamente de duas formas. Por um lado, há movimentos radicais como o construcionismo social em que discussão respousa muito mais sobre os núcleos de inteligibilidade, onde as crenças e conceitos são partilhados pela comunidade, de que sobre a questão ontológica, sobre o qual o construcionismo nada tem a afirmar $^{4}$ (Gergen, 1996). A noção central de um mundo

\footnotetext{
${ }^{3}$ Embora os autores pós-modernos nem sempre enfatizem explicitamente o tema da subjetividade, entende-se, no presente artigo que a questão da linguagem se constitui em um momento fundamental desse tema.

${ }^{4}$ No dizer de Gergen (1996) o construcionismo social é ontologicamente mudo.
}

construído na linguagem que permeia as pautas sociais acompanhará a obra de diversos terapeutas (Andersen, 1996; Anderson \& Goolishian, 1988; 1996; Gergen \& Kaye, 1998; White \& Epston, 1993) que propõem importantes contribuições neste campo, como também severas críticas ao paradigma dominante no modernismo presente na psicologia clínica. Contudo, apesar de trazer contribuições de grande relevância para a compreensão da subjetividade, tais propostas padecem de uma influência simplificadora, em que não existe espaço para a dimensão ontológica, mas apenas para a construção de significados no seio das comunidades. Além disso, o humano fica reduzido às construções lingüísticas e à pauta interativa. Desprezam-se, portanto, momentos importantes da construção do saber, como as resistências do real ${ }^{5}$, e as facetas múltiplas da subjetividade que abarcam as tramas da linguagem e do social, mas não se esgotam nelas. Baseados em críticas desse teor, autores como Mahoney (1991) e Gonzalez Rey (1997) têm qualificado a influência pós-moderna numa postura mais condizente com esses dois pontos.

\section{Obstáculos Epistemológicos Como Erros e Possibilidades ao Espírito Cientifico}

Como se pode notar, o problema da subjetividade sai gradativamente de uma posição marginal para uma posição central, onde suas questões são problematizadas e suas relações com o conhecimento são assumidas. Por essas razões, compreende-se que a psicologia poderá ser alçada a uma nova posição uma vez que novos campos de investigação passam a se delinear para sua atuação, abrangendo um elo complexo e recursivo entre as condições que envolvem o conhecimento em sua criação e processo (individuais, sociais, míticas, emocionais) e o conhecimento gerado (com seus objetos complexos principalmente). No entanto, é necessário ainda que acompanhe todo um processo de reflexão epistemológica em si mesma, de maneira que, transformando-se, ela possa oferecer contribuições significativas para a transformação de paradigma presente na atualidade (Morin, 1996, 1998; Neubern, 1999; Santos, 1987, 1989). Dito de outro modo, é preciso que proceda à construção de novas visões sobre a subjetividade enquanto objeto de estudo e, ao mesmo tempo, comprometa-se com uma observação atenta sobre seus pressupostos de investigação, apesar dos riscos que isso envolve (Koch, 1981). Diante

\footnotetext{
${ }^{5}$ Resistência ao real consiste em uma noção epistemológica (Gonzalez Rey, 1997; Mahoney, 1991; Morin, 1996) segundo a qual a realidade não se acomoda passivamente às construções teóricas, podendo, por seu papel ativo levá-las a reformulações.
} 
das novas necessidades e contradições que a investigação aberta do real impõe, os erros epistemológicos do passado podem ser retificados num processo que dê abertura para o novo, a criação e a inventividade, tão caros ao espírito cientifico (Bachelard, 1985).

É nesse ponto que a psicologia clínica pode contribuir, inclusive a partir de uma reflexão atenta sobre os obstáculos epistemológicos. As grandes dificuldades presentes no cotidiano da clínica, decorrentes geralmente da natureza complexa da subjetividade e em grande parte subversivas ao pensamento dominante podem vir a ser sua grande virtude para a implantação de uma forma de pensar condizente com o espírito científico. A multiplicidade de dimensões complexamente articuladas ao longo de um processo histórico impõem a necessidade de um saber que possa dialogar com o real e suas resistências e pode se constituir em um aliado importante contra as patologias que enrijecem e cegam o conhecimento (Koch, 1981; Morin, 1990).

Os obstáculos epistemológicos referem-se, portanto, aos erros de pensamento que se contrapõem ao espírito científico e devem ser retificados para que o mesmo se implante. Porém, deve-se apontar que tais obstáculos geralmente se encontram presentes de três formas, comumente entrelaçadas, na práxis da psicologia clínica. Primeiramente, encontram-se nas limitações de abordagem dos pressupostos epistemológicos, comumente de origem empirista (Bercherie, 1986), diante das questões trazidas pela subjetividade. Embora Bachelard (1996) não tenha teorizado sobre este ponto, pode-se compreendê-lo como uma idéia condizente com sua noção de obstáculo, uma vez que boa parte das escolas de psicologia parecem cometer um erro fundamental ao construir seus objetos de estudo com base em cosmovisões originárias de outros campos de conhecimento (Anderson \& Goolishian, 1996) ${ }^{6}$.

Em segundo lugar, encontra-se o próprio pensamento do pesquisador ou terapeuta que, imbuído de conceitos consagrados da psicologia tradicional, procede a inúmeras racionalizações em meio a idéias dogmáticas e fechadas que não permitem um diálogo efetivo com as questões trazidas pela subjetividade. Trata-se praticamente da postura intelectual que o pesquisador adota diante desses problemas que contribui sobremaneira para a confirmação de sua escola de psicologia como doutrina. E, finalmente, há a própria questão da institucionalização do pensamento que favorece com que uma proposta, originalmente

\footnotetext{
${ }^{6}$ Pode-se recomendar para o aprofundamento desse tópico as obras de Gonzalez Rey (1997) e Neubern (1999).
}

destinada a um diálogo com o real, transforme-se em um sistema doutrinário, descaracterizado em sua cientificidade. Nesse sentido, seria necessária uma abordagem mais abrangente que pudesse abarcar a dinâmica das comunidades científicas em suas dimensões intersubjetivas, sociológicas, políticas e econômicas, o que não cabe no escopo deste artigo. A psicologia a clínica pode fornecer inúmeros exemplos em que o pensamento dos mestres é assassinado por escolas de discípulos muito fiéis onde o pensamento crítico não é bem vindo e dificilmente encontra espaço. Desconhece-se a própria assertiva de Bachelard (1996) de que “(...) na obra da ciência só se pode amar o que se destrói, pode-se continuar o passado negando-o, pode-se venerar o mestre contradizendo-o" (p. 309). Ao mesmo tempo, a doutrinarização dos pensamentos psicológicos mereceria, em um momento posterior, um estudo mais aprofundado com as próprias dimensões políticoeconômicas do cenário social, como as teorias da moda e o próprio mercado $p s i$ em suas diversas faces e exigências.

Desse modo, o presente trabalho centra sua análise nas duas primeiras formas acima apontada, pois fornecem consideráveis informações para a construção de obstáculos epistemológicos no pensamento do pesquisador. Isso não impede que vez por outra sejam feitas referências ao terceiro aspecto. Procura destacar como os obstáculos ao espírito científico se constituem em erros fundamentais da subjetividade do investigador na construção do conhecimento psicológico. Mais especificamente, destacam-se três obstáculos sobre a forma como o sujeito constrói o conhecimento, ao mesmo tempo em que apontar caminhos para sua retificação, caminhos esses baseados em princípios metodológicos, teóricos e epistemológicos mais condizentes com o universo complexo da subjetividade (Gonzalez Rey, 1997, 1999; Morin, 1996, 1998). Uma vez corrigidos, tais obstáculos poderão fornecer subsídios para passos iniciais na construção de uma visão mais abrangente sobre o espírito científico na psicologia clínica como na psicologia com ciência. Foram escolhidos apenas três obstáculos epistemológicos para serem discutidos, pois, além das limitações de espaço, entende-se que a proposta de destacá-los, discuti-los à luz de pressupostos complexos de modo a traçar caminhos para sua retificação, pode ser extensiva a boa parte deles ${ }^{7}$. Tais

\footnotetext{
7 A noção de obstáculo epistemológico provém de Bachelard (1996) onde podem ser encontrados numerosos exemplos para o conhecimento científico em geral. Outros autores como Gonzalez Rey (1997, 1999), Koch (1981), Morin $(1990,1998)$ e Neubern (1999) fornecem instrumentos bastante interessantes para refletir sobre os possíveis e numerosos obstáculos epistemológicos na psicologia.
} 
obstáculos serão analisados a partir de um breve relato de caso clínico, em que é possível denunciar sua presença.

\section{O Caso Ademar Silveira}

Ademar Silveira, 60 anos, alto funcionário de uma empresa, procurou os serviços de uma clínica onde havia encerrado há alguns anos uma psicoterapia. Alegou que os profissionais já o conheciam e que não gostaria de repetir novamente sua história. A princípio, ele apresenta uma queixa difusa, um mal estar muito ligado ao ambiente de trabalho, cheio de armadilhas e falcatruas, segundo ele. Porém, ao longo do trabalho, ele começa a perceber que muitas de suas decisões pareciam apontar para um caminho que ele mesmo pontuou da seguinte forma: "tenho que dizer um sim a mim mesmo. Devo optar por qualidade de vida!" Ademar foi aos poucos percebendo o tipo de conflito em que sua vida parecia se encontrar. Por um lado, um ambiente com muitas exigências e inimigos, que poderia lhe facultar maior ascensão profissional, mas que também era muito desgastante. Seus momentos de irritação eram taxados como loucura, fato de que seus rivais tiravam proveito. Por outro lado, Ademar pouco a pouco se apercebia de que já havia começado a buscar novas qualidades de vida e relação. Havia se tornado ao longo de sua vida, na família ou no trabalho, um homem rígido, decidido e comumente agressivo, apto a enfrentar as dificuldades. No entanto, determinadas decisões que havia tomado, dificultavam sua carreira profissional, mas ao mesmo tempo o poupavam de situações de conflito. Ele se aproxima mais do filho deficiente (por quem manifestou vergonha por muito tempo) atrasando-se em seus compromissos para levá-lo na escola. Passa a acompanhar mais de perto os projetos dos outros filhos, adotando uma postura distinta da punição habitual quanto aos mesmos.

Contudo, em certa ocasião, sua esposa Joana procura os profissionais da clínica manifestando grande preocupação. Ela relata que no domingo, o filho mais velho foi buscá-la em outro cômodo da casa afirmando que seu pai estava na sala, chorando. Quando ela o encontrou, alegou estar muito assustada, pois nunca o havia visto dessa forma. Procuraram, então, pelo psiquiatra que prescreveu um aumento da medicação. Joana passou também a trazer muitos conflitos do casal, pois, em sua visão, uma mulher forte deveria merecer um homem forte. Chegou mesmo a comentar sobre a possibilidade de divórcio.

\section{Os Obstáculos Epistemológicos \\ O Conhecimento Geral e Totalitário}

Esse obstáculo consiste basicamente na primazia de categorias gerais em detrimento de significações e sentidos singulares. Dito de outro modo, o singular é, de diferentes formas, absorvido, excluído ou desconsiderado pelo geral. Consiste em uma herança moderna em que as generalizações eram tidas como condição de cientificidade. Como a complexidade era vista como aparência do real, cabia ao cientista ir além do aparente e desvendar leis simples e universais (Santos, 1987; Morin, 1998). A psicologia qualificou tal influência em meio a noções muito propícias à construção de leis universais, como o individualismo e a natureza humana, que favoreciam considerável desvinculação quanto à dialética social, cultural e histórica presentes na constituição dos sujeitos. Nesse sentido, noções como os quadros nosográficos do DSM IV (1995) ou as estruturas de personalidade (Bergeret, 1988) são bastante ilustrativas, pois apontam para modelos transcendentais.

Um dos grandes problemas que se desenvolveu nesse obstáculo é que o esforço original de autores como Freud (1969) que buscavam uma relação em que o singular não fosse absorvido no geral (como quando discorria sobre o sentido dos sintomas) foi freqüentemente sobrepujado pelas perspectivas universais e absolutas. Uma vez que todos os motivos humanos conduziam, de uma forma ou outra, à sexualidade e que o núcleo da neurose era necessariamente ligado ao conflito edípico, não se constituíram alternativas de compreensão ligadas a outras temáticas relacionadas com a história de vida dos sujeitos construída ao longo de múltiplos processos da ação social. Desse modo, a própria teoria tornou-se ditadora do pensamento de investigadores e terapeutas, pois, ao invés de se constituir em uma fonte de referências para o diálogo com o diverso presente na subjetividade, constituiu-se em um sistema de imposições de conceitos e visões de mundo.

Os comentários e discussões traçados por profissionais sobre o caso de Ademar são bastante ilustrativos quanto a isso ${ }^{8}$. A princípio, ele é definido como neurótico obsessivo cujas defesas começam a apresentar falência em meio ao conflito psíquico. A depressão seria advinda do montante de energia represada sem uma resolução pulsional. Além disso, considera-se que Ademar encontra grandes dificuldades no atual momento, pois o trabalho da terapia o leva a entrar em contato com as emoções, tarefa difícil para seu ego. A medicação entraria como um fator útil por possibilitar um contato menos turbulento com tais emoções.

\footnotetext{
${ }^{8}$ Nesse sentido, não há muita diferença entre os comentários traçados e uma análise mais criteriosa, pois ambos se baseiam nos mesmos pressupostos epistemológicos e na mesma ausência de crítica sobre os mesmos.
} 
Malgrado a utilidade de tais conceitos como forma de compreensão do problema, eles não deixam de se constituir como obstáculo epistemológico, principalmente pela postura intelectual em que se configuram. Primeiramente, o conflito vivenciado por Ademar, que aponta claramente para significações, sentidos e necessidades entre contextos e processos incompatíveis, é transposto para um modelo universal, onde impera a batalha entre as forças pulsionais e a interdição cultural. Logo, os contrastes envolvendo construções sobre as disputas com os colegas, as exigências da esposa e dos amigos e suas necessidades de qualidade de vida praticamente são diluídos ou subjugados por um esquema da natureza humana absoluta onde devem existir mecanismos que garantam defesas contra as ameaças inconscientes de ordem sexual. O mecanismo hidráulico de energias represadas e acumuladas sobrepõe-se à toda diversidade de possibilidades de conflito.

Nessas apreciações não se considera um problema essencial para a compreensão da subjetividade, que é a questão dos sentidos. Em momento algum, Ademar dá espaço para a interpretação apressada de que seus problemas estejam ligados a conteúdos libidinais e que estes mantenham uma oposição às interdições da cultura. Se a subjetividade implica em um jogo dialético entre o sujeito e o mundo social, logicamente suas necessidades derivarão de uma complexa construção originada dessa relação e não de uma oposição à priori entre duas dimensões. Os sentidos, portanto, devem ser interpretados em função do diálogo com o cenário subjetivo (individual e social) em que Ademar se constitui (Gonzalez Rey, 1997, 1999; Gergen, 1996). As necessidades, por sua vez, não obedecem a uma tentativa de superação da oposição contumaz ao recalque, mas a um processo de construção de novas qualidades relacionais e de significação, cujos obstáculos não necessariamente obedecem à descrição do recalque psicanalítico. No caso de Ademar, deve-se compreender que as múltiplas faces de sua subjetividade possibilitam inúmeras configurações (Gonzalez Rey, 1997) que podem se organizar de acordo com seus contextos relacionais. O dizer um sim a si mesmo e a qualidade de vida a que ele se refere, implicam em sentidos específicos para circunstâncias específicas: com respeito aos filhos, a necessidade de uma troca afetiva distinta; a necessidade de construir novos sentidos em uma história marcada pela distância e agressividade. Quanto ao trabalho, a possibilidade da revolta e mesmo de ruptura com esse universo. Mesmo que tais necessidades possuam algo comum, é importante ressaltar as diferenças singulares que qualificam a diversidade subjetiva de um único sujeito.
Outro ponto que chama a atenção na análise dos profissionais, é a forma dicotomizada em que as emoções são situadas quanto ao racional de Ademar, como se suas expressões fossem destituídas desse processo. A compreensão decorrente dessa análise imporia, por conseguinte, a noção de que existem pessoas que entram em contato com mais facilidade com suas emoções do que outras. Essa noção apresenta um equívoco inicial que não pode passar despercebido: se as emoções são constituídas no seio de um processo subjetivo, não faz sentido conceber pessoas que não mantenham alguma interação com elas. Efetivamente, deve-se considerar que para alguns momentos da subjetividade de certas pessoas, haja maiores dificuldades de construir novos significados sobre os processos emocionais, o que as leva com freqüência, como no caso de Ademar, a um mal estar indefinido (Neubern, 1999). Contudo, não se pode ceder aos apelos da simplificação para concebê-las como um processo alheio ao sujeito, como se a subjetividade mantivesse departamentos rigidamente separados.

Por outro lado, ainda há um ponto levantado que merece maior atenção. A organização da subjetividade obedece a uma lógica configuracional (Gonzalez Rey, 1997, 1999) o que não comporta a dicotomia emoção cognição. Nessa lógica, as configurações implicam em sistemas que integram simultaneamente processos de significação e emoção que podem permitir múltiplos arranjos na trajetória do sujeito. Logo, necessidades, motivos, estados e sentidos integram-se de forma configuracional, o que permite uma compreensão da diversidade de momentos emocionais. No caso de Ademar, ao invés de se conceber que ele possui dificuldades para entrar em contato com suas emoções, pode-se pensar a questão em função da multiplicidade de faces presentes na construção e constituição da subjetividade. A princípio, mesmo nos momentos em que, ao longo de sua história, ele atuou de forma mais ríspida e racional, Ademar desenvolveu emoções muito intensas (como a agressividade, amor ao poder), que mesmo nas circunstâncias atuais podem ser de grande valia para seu trato social. Por outro lado, em meio às possibilidades do novo que começam a surgir em sua vida, ele passa a se deparar com novas qualidades emocionais, o que pode ter sido assustador tanto para ele, como para seus colegas e esposa. A diversidade presente em cada um desses momentos não permite, em conseqüência, conceber ausência de contato com suas emoções ou ainda dificuldades em lidar com elas: isso pode ocorrer com algumas, mas não todas, principalmente caso se observe a diversidade de 
momentos e circunstâncias de seu cotidiano, onde tais processos necessariamente estão presentes.

Finalmente, categorias como sentidos, configurações e emoções podem se constituir como universais, desde que não assumam um status transcendental e absoluto com os mecanismos já descritos de exclusão da subjetividade. É nessa direção que Bachelard (1996) aponta para a necessidade de um pensar inquieto diante do consagrado e do homogêneo:

"É assim que, em todas as ciências rigorosas, um pensamento inquieto desconfia das identidades mais ou menos aparentes e exige sem cessar mais precisão e, por conseguinte, mais ocasiões de distinguir. Precisar, retificar, diversificar são tipos de pensamento dinâmico que fogem da certeza e da unidade, e que encontram nos sistemas homogêneos mais obstáculos do que estímulo. Em resumo, o homem movido pelo espírito científico deseja saber, mas para, imediatamente, melhor questionar." (p.21).

A psicologia clínica encontra, portanto, diante do obstáculo do geral totalitário um desafio considerável. A tendência à homogeneizar pessoas, formas de terapia, visões sobre problemas e mudança acarreta em conseqüências graves, intrinsecamente ligadas à exclusão da subjetividade. Vão desde a prescrição desenfreada de psicoterapias, sem a mínima reflexão crítica sobre suas indicações e limitações, a uma enorme parcela de sujeitos, em geral de classes desfavorecidas, para quem os procedimentos da psicologia clínica não fazem sentido algum. Contudo, é necessário que o problema seja refletido em outras dimensões ${ }^{9}$ que vão além do obstáculo epistemológico, mas que desenvolvem com ele intensa retroalimentação.

\section{A Tendência Patologizante e Incapacitadora (Os Becos Sem Saída)}

Tal obstáculo implica basicamente na determinação de uma visão de mundo em que as expressões do sujeito são compreendidas via-de-regra pelo prisma da patologia ou da incapacidade. De certa forma, costuma acompanhar vários momentos do sujeito conferindo-lhes atributo doentio, ao mesmo tempo em que exclui ou desconsidera outros momentos que podem confrontar a dominação dessa narrativa (White \& Epston, 1993). No caso de Ademar, o choro é tomado como um momento de loucura e depressão, ao passo que sua proximidade quanto aos filhos e as demandas que aos poucos passa a construir para uma qualidade de vida diferente são praticamente desapercebidos.

\footnotetext{
${ }^{9}$ Como a formação de terapeutas, as exigências do mercado e a mitologia cultural que envolve a terapia.
}

Aliada comumente ao conhecimento geral e totalitário, a tendência patologizante com muita freqüência é envolvida pelo determinismo. Uma vez que a estrutura de personalidade se defina (Bergeret, 1988), resta à diversidade numerosa de sujeitos o fatídico destino da classificação neurótica ou psicótica ou ainda uma variação de uma dessas estruturas de base. A própria normalidade, talvez como herança da metáfora do cristal da psicanálise, é compreendida como um momento funcional e muitas vezes frágil de uma base estrutural doentia. Gergen e Kaye (1998) apontam que essa herança modernista tem como base os pressupostos de que há uma causa latente ou base da patologia, localizada dentro dos clientes ou em suas relações que podem ser diagnosticados e, por meios específicos, serem eliminados ou tratados. No entanto, os mesmos autores apresentam críticas incisivas quanto às limitações dessas premissas, sobretudo pela desconsideração que dispensam às narrativas dos sujeitos e as limitações que impõem sobre novas possibilidades de construção.

O homem doente torna-se, então, a referência universal de avaliação das expressões múltiplas da subjetividade. Nesse sentido, encontra-se o problema, também levantado por Gergen e Kaye (1998), da imposição de narrativas em que toda uma cosmovisão respaldada pelo saber científico vai se impondo sobre um conjunto de histórias e processos construídos ao longo de toda uma vida. Tal imposição, ao mesmo tempo em que é alheia aos processos de significação próprios do sujeito, ignora as diversas articulações em torno do problema que contribuem para sua construção e que freqüentemente podem denunciar a sabedoria que tal expressão tida como patológica pode comportar (Anderson \& Goolishian, 1988; Ausloos, 1995). O choro de Ademar é revelador de uma tentativa corajosa e sofrida de mudança de vida, principalmente pela tentativa de resgatar valores e qualidades relacionais importantes para ele, mas incoerentes com seus contextos sociais.

Outro ponto com o qual a tendência patologizante comumente se entrelaça é a perspectiva individualista ${ }^{10}$, o que consiste em um artifício poderoso de exclusão da subjetividade por não considerar a diversidade de processos de subjetivação envolvidos na construção do problema. Ao se firmar a noção de que o problema está determinado na estrutura individual, perde-se uma

\footnotetext{
${ }^{10} \mathrm{O}$ individualismo coloca o indivíduo como fonte da patologia. No entanto, todo pensamento que colocar um ponto específico como a causa do problema (como a família ou os processos neurológicos) desconsiderando a complexidade de fatores organizados ao redor do problema obedece ao mesmo princípio simplificador do individualismo.
} 
dimensão fundamental na consideração da subjetividade: a construção do problema que está vinculada aos múltiplos sistemas subjetivos que se organizam em torno dele $^{11}$ (Neubern, 1999). Desse modo, ao se classificar o quadro de Ademar como depressivo, acentua-se comumente seu aspecto estrutural e o determinismo neurológico nele presente, mas descontextualiza-se seu sofrimento com respeito aos processos sociais e institucionais que necessariamente promovem a construção da depressão do sujeito. Perde-se mesmo a noção de poderosos mecanismos que ordenam tal construção, como aqueles presentes na própria determinação de visões de mundo (as expressões de choro, os rompantes de humor, as alterações do sono são indícios de depressão) ou ainda nas ameaças de retaliação social a que a fraqueza de Ademar está sujeita (como as ameaças dos colegas e de divórcio). Tais processos envolvem facetas diversificadas e amplas (Foucault, 1997; Goffman, 1999; White \& Epston, 1993) e merecem estudos mais aprofundados, principalmente quanto à participação ativa do sujeito nessas construções.

Portanto, o estudo da subjetividade requer uma requalificação radical da tendência patologizante. Devese, por um lado, reconhecer as influências individuais e suas determinações sem, contudo, ceder à suas tentações absolutistas sob a forma do individualismo e do determinismo. Deve-se, por outro lado, reconhecer que a subjetividade não é essencial e estruturalmente doentia e que, qualquer abordagem sobre ela, deve necessariamente privilegiar seus cenários de sentido, de modo que seja possível uma visão aprofundada do sofrimento em seus múltiplos circuitos de construção. A complexidade envolvendo o problema subjetivo consiste em um desafio, pois a compreensão de suas múltiplas articulações pode permitir importantes redefinições e ativações de potencial (Ausloos, 1995). É nesse sentido que Morin (1983) fornece instrumentos para pensar a questão:

"Há, pois, zonas fracas do 'imprinting', da normalização, da determinação, onde o desvio pode aparecer, eventualmente desenvolver-se e tornar-se tendência. Por isso, é necessário ver não só o tecido determinista, mas também as falhas, os buracos, as zonas de turbulência, os cachões da cultura, onde, efetivamente, brota o novo." (pp. 27-28)

\footnotetext{
${ }^{11}$ Essa noção é tomada de Anderson e Goolishian (1988) segundo a qual "os problemas criam sistemas". Porém, Neubern (1999) toma essa consideração acrescentando dois aspectos: os sistemas não são apenas lingüísticos, mas subjetivos; tal noção não deve se contrapor à criação de problemas pelos sistemas, principalmente pelas múltiplas causalidades lineares que podem existir, articulando-se em sua construção.
}

\section{As Conclusões Apressadas}

As conclusões apressadas consistem em um obstáculo típico da racionalização presente no pensamento científico (Morin, 1998), como também na psicologia clínica. Diante de um fenômeno qualquer, como as crises de Ademar, suas expressões são classificadas de modo automático e mecânico em categorias e noções consagradas. As contradições e problemáticas presentes no real, que podem ser ameaçadoras e desconfortáveis, desaparecem de forma mágica. Esse tipo de facilidade parece estar ligado a múltiplos fatores, que variam desde o projeto científico de poder e controle da realidade a questões oriundas do consumismo de idéias, em que um conjunto de receitas práticas pode poupar muitas dificuldades ${ }^{12}$.

Apresentando-se muito integrado aos obstáculos já discutidos, as conclusões apressadas costumam se manifestar na clínica por meio do uso abusivo de categorias e concepções a priori. Consistem, dessa forma, em um poderoso recurso de exclusão que descontextualiza quase que por completo a diversidade de questões subjetivas que perpassam uma queixa. Promovem uma cegueira sistematizada que busca classificar o já conhecido e não procura se aventurar pelos aspectos que se mostram distintos, nebulosos, irregulares e estranhos diante das noções consagradas. Desprezam o sentido do espírito científico segundo o qual (Bachelard, 1985): “Os conceitos e métodos, tudo é função do domínio da experiência; todo o pensamento científico deve mudar ante uma experiência nova; um discurso sobre um método científico será sempre um discurso de circunstância, não descreverá uma constituição definitiva do espírito científico.” (p.121)

Boa parte dos motivos que propiciam tal obstáculo ligam-se a um problema da própria tradição psicológica que legou aos métodos clínicos uma validade restrita, pois só seriam condizentes com o setting clínico, como se a subjetividade fosse exclusiva desse contexto (Gonzalez Rey, 1996). Além disso, considerou sua validade duvidosa por elaborar procedimentos teóricos e metodológicos que buscavam atender às exigências dos objetos de estudo, mas afastavam-se do rigor e das prescrições confiáveis no parecer científico. As conseqüências para a psicologia clínica refletem-se de modo a acentuar a drástica mutilação entre conhecimento de pesquisa e conhecimento

\footnotetext{
${ }^{12}$ Logicamente, não se pode desconsiderar a presença desses obstáculos na formação profissional de terapeutas. Antes de criticar o consagrado é preciso conhecê-lo e, muitas vezes, apegar-se a ele. Além disso, existem situações, como a ala psiquiátrica de muitos hospitais públicos, em que tais conclusões possuem função especial. Porém, em ambos os casos não se pode desprezar a necessidade do espírito crítico.
} 
prático, ainda muito presentes na atualidade. No primeiro desses eixos, há a possibilidade da aplicação de recursos como o psicodiagnóstico que, calcado em procedimentos estandardizados como os testes psicométricos e projetivos, é muitas vezes utilizado de modo estanque quanto ao processo terapêutico e comumente mais valorizados do que este. No outro eixo, encontra-se a psicoterapia, onde o saber consagrado dita regras de classificação e procedimento que, quando não afastam o terapeuta do contato aberto com as contradições e dificuldades da realidade dos pacientes, podam suas possibilidades criativas diante de tais problemas, principalmente se as mesmas se apresentam como subversivas ao pensamento dominante.

No entanto, há ainda uma dimensão marginal presente nas construções e intervenções de muitos clínicos que, embora não seja compreendida como possibilidade de pesquisa, contribui significativamente para os processos de mudança de seus pacientes. Tal dimensão comumente não é sistematizada em suas construções e muitas vezes não aparece como confronto explícito aos marcos teóricos de referência em que se baseiam. Contudo, parecem fazer considerável referência ao que Mahoney (1991) considera como a novidade na psicoterapia, um dos momentos fundamentais para a mudança, que não diz respeito a uma teoria transcendental e estabelecida, mas a um conjunto de habilidades que permitem ao terapeuta construir, em diferentes níveis, sobre dimensões essenciais desse processo, como o vínculo, a comunicação, o acontecimento, a criação e as vivências subjetivas, onde as emoções desempenham papel central.

Esse conjunto de obstáculos, intrínsecos ao conhecimento institucionalizado, propicia a adoção das conclusões apressadas basicamente de dois modos. Além de fornecer um conjunto de noções estandardizadas e respaldadas, não legitima, como momento da pesquisa, as construções que o terapeuta necessita realizar em seus momentos empíricos. O espírito científico é condenado ao silêncio (ou à morte, em muitos casos) justamente porque a condição de sujeito ativo da pesquisa não é conferida ao terapeuta. Para que o contrário ocorra devese reconhecer que, sob certos parâmetros, o pensamento do terapeuta deve ser qualificado, de modo que suas construções sobre o processo singular sejam legitimadas, mesmo que às vezes contrárias à teoria que o respalda (Gonzalez Rey, 1999; Neubern, 1999). A pesquisa realizase necessariamente entre esses pólos de tensão - o pensamento do sujeito e a teoria estabelecida - pois a relação entre ambos torna possível de modo mais efetivo a relação entre o corpo teórico construído na comunidade e os momentos singulares que constituem a prática profissional. Tal perspectiva, ao situar a pesquisa como geração de pensamento, rompe a dicotomia entre a prática clínica e a pesquisa. Entretanto, deve-se destacar que o reconhecimento da subjetividade do sujeito não deve implicar em um subjetivismo absoluto contrário a qualquer rigor metodológico, mas a um conjunto de processos de mudanças epistemológicas no próprio conhecimento (objetivado em muitos de seus momentos) onde seja possível assumir a participação de seu criador.

\section{Conclusão: Reconhecer a Subjetividade Implica em Utopias}

O reconhecimento da subjetividade para a psicologia clínica, como para a ciência, possui implicações das quais os obstáculos epistemológicos são apenas um momento. A discussão remete a um universo muito mais amplo que não caberia discutir aqui (Gonzalez Rey, 1997, 1999; Morin, 1998; Neubern, 1999). Por outro lado, para efeito de conclusão, destaca-se que reconhecer a condição humana como ponto central na construção do conhecimento implica em uma discussão de utopias sobre sua participação como objeto de estudo ou como momento fundamental do espírito científico.

Como objeto de estudo, a subjetividade deve consistir em um conjunto de noções fundamentais que exijam saber aberto e mentalidade de investigação, isto é, um apelo persuasivo ao espírito científico. Suas diversas características remetem-na como objeto de estudo complexo que procura articular dimensões classicamente opostas no pensamento psicológico (Gonzalez Rey, 1997; Morin, 1996). No entanto, embora tal concepção seja assumida em termos ontológicos, ela nada possui de absoluta, pois isso implicaria em novas posturas ditatoriais e universalistas, pretensamente capazes de impor noções únicas de homem e formas também únicas de estudá-lo. É interessante observar que muito mais que uma proposta absoluta e substancializada de um objeto específico e isolado, o que se busca é basicamente traçar formas de construção de pensamento que possam dialogar com uma realidade viva, presente no cotidiano, que sente, decide, pensa, sonha, mas que até o momento permanece, enquanto ser integral, uma incógnita diante do conhecimento que ela mesma criou.

Como condição básica do espírito científico, seu papel centra-se no diálogo com qualidades emergentes (como a invenção, a inquietação, a arte) que podem garantir o movimento constante da geração de pensamento para quem uma resposta não implica em conclusões finais, mas em momentos de um conhecimento incompleto. Toda a flexibilidade inerente ao espírito científico não deve ser enfocada apenas em termos de indivíduos, pois 
para tanto há condições macrossociais que a favorecem. No entanto, longe de consistir em um ponto morto como assevera Gergen (1996), o sujeito consiste em um momento imprescindível nessa compreensão, capaz de promover rupturas nas grandes estruturas do paradigma (Morin, 1998).

No caso da psicologia clínica, a sua pluralidade, atestado de ilegitimidade científica na visão dominante, pode vir a consistir em ponto favorável ao espírito científico. A diversidade de visões pode favorecer muitos guetos onde as determinações do paradigma não alcançam ou são mais frágeis, o que possibilita a construção de alternativas. Em termos da construção da subjetividade como objeto complexo, a pluralidade de vozes pode contribuir significativamente para sua compreensão como Unitas Multiplex (Morin, 1996, 1998; Neubern, 1999). Nesse ponto, uma das principais funções do espírito científico é a possibilidade de qualificar as diversas contribuições, num processo que permita uma forma radicalmente distinta e complexa de pensar. Porém, embora o sujeito não necessite de sistemas de conhecimento abertos à integração para possibilitar o espírito científico, para um pensamento articulador devem ser cogitadas mudanças simultâneas em níveis mais amplos onde o diálogo possa se construir entre escolas distintas. Esse é um grande desafio, pois os sistemas de idéias em geral são autocêntricos e intolerantes com pensamentos distintos. Portanto, uma primeira utopia que envolve o espírito científico, é uma democracia de idéias, onde o diálogo seja possível para construir sobre a subjetividade, malgrado todas as antipatias, turbulências e conflitos que a democracia também comporta (Neubern, 1999).

Por fim, a empresa desse texto traz à tona a necessidade de um compromisso efetivo com uma nova noção de psicologia e de clínica. A ciência não consiste em um conhecimento, estático, substancializado e universal, mas na possibilidade de um conbecer em que as respostas ainda não foram dadas e, quando o forem, permitirão a criação de novas perguntas. Conhecer implica no sujeito que dialoga com o objeto de estudo e simultaneamente com as múltiplas teias que perpassam seu cenário de estudo. É um apelo veemente para alertar os psicólogos de que o conhecimento e a clínica que são construídos estão profundamente relacionados com os pensamentos vigentes na sociedade. Entretanto, a condição de sujeito tem encontrado um considerável desafio com respeito ao próprio conhecimento: em alguns momentos é escrava, enquanto em outros é marginal. Além disso, os vários obstáculos que se opõem à mesma no cenário social (que surgem em certos momentos como ameaças de retaliação em outros como comodismo ou seduções) concorrem intensamente para que a condição de sujeito seja bastante incomum no cenário social. Logo, para que o cientista possa sonhar com a condição de sujeito, enquanto base do espírito científico, deve buscar uma segunda utopia: uma postura de cidadania com relação ao próprio conhecimento, para que o mesmo possa também se constituir em conhecer.

\section{Referências}

American Psychiatric Association (1995). Manual diagnóstico e estatístico de transtornos mentais - DSM IV (D. Batista, Trad.). Porto Alegre: Artes Médicas. (Original publicado em 1994)

Andersen, T. (1996). Processos reflexivos (R. Bergallo, Trad.). Rio de Janeiro: Noos/Itf. (Original publicado em 1991)

Anderson, H. \& Goolishian, H. (1988). Human systems as a lingüistic systems: Preliminary and evolving ideas about the implications for clinical theory. Family Process, 27, 371- 394.

Anderson, H. \& Goolishian, H. (1996). A noção de self: Alguns dilemas pós modernos na psicoterapia. Em D. Fried-Schnitman (Org.), Novos paradigmas, cultura e subjetividade (J. H. Rodrigues, Trad.) (pp. 191 - 203). Porto Alegre: Artes Médicas. (Original publicado em 1994)

Ausloos, G. (1995). La competénce des familles. Paris: Érès

Bachelard, G. (1985). O novo espirito cientifico. (J. Hahne Jr, Trad.). São Paulo: Tempo Brasileiro. (Original publicado em 1934)

Bachelard, G. (1996). A formação do espirito científico. (E. Abreu, Trad). Rio de Janeiro: Contraponto. (Original publicado em 1938)

Bercherie, P. (1986). Los fundamentos de la clínica. Buenos Aires: Manantial.

Bergeret, J. (1988). Personalidade normal e patológica (A . Fillmann, Trad.) Porto Alegre: Artes Médicas. (Original publicado em 1974)

Freud, S. (1969). Conferências introdutórias sobre psicanálise. (M. Rego, Trad.). Em J. Salomão (Org.), Edição standard brasileira de obras completas de Sigmund Freud. (Vol. 22). Rio de Janeiro: Imago (Original publicado em 1937)

Foucault, M. (1997). Resumo dos cursos do Collège de France (1970-1982) (A Dahar, Trad.) Rio de Janeiro: Zahar. (Original publicado em 1994)

Gergen, K. (1996). Realidades e relaciones. Barcelona: Paidós

Gergen, K. \& Kaye, J. (1998). Além da narrativa na negociação do sentido terapêutico (C. Dornelles, Trad.). Em S. Mc Namme \& K. Gergen (Org.), A terapia como construção social (pp. 201-222) Porto Alegre: Artes Médicas. (Original publicado em 1995)

Goffman, E. (1999). Manicômios, prisões e conventos. (D. Leite, Trad.). São Paulo: Perspectiva. (Original publicado em 1961)

Gonzalez Rey, F. (1996). Problemas epistemológicos de la psicología. Havana: Academia.

Gonzalez Rey, F. (1997). Epistemología cualitativa y subjetividad. Havana: Pueblo y Educacion.

Gonzalez Rey, F. (1999). La investigacion cualitativa: Rumbos y desafios. São Paulo: Puc-Educ.

Koch, S. (1981). The nature and limits of psychological knowledge. American Psychologist 3, 257-269.

Kuhn, T. (1996). A estrutura das revoluções científicas (B. Boeira \& N. Boeira, Trads.) São Paulo: Perspectiva. (Original publicado em 1970)

Lyotard, J. (1979). La condition postmoderne. Paris: Minuit.

Mahoney, M. (1991). Human change process. New York: Basic Books.

Morin, E. (1983). O problema epistemológico da complexidade. Mem Martins: Europa-América.

Morin, E. (1990). Introduction à la pensée complexe. Paris: Esf.

Morin, E. (1996). Ciência com consciência. (M. Alexandre \& Dória M., Trad.) Rio de Janeiro: Bertrand Brasil. (Original publicado em 1982 e 1990)

Morin, E. (1998). O método: As idéias: Habitat, vida, costumes, organização. (J. Silva, Trad.), Porto Alegre: Sulina. (Original publicado em 1991) 
Neubern, M. (1999). Fragmentos para uma compreensão complexa da terapia familiar: Diálogos epistemológicos sobre as emoções e a subjetividade no sistema terapêutico. Dissertação de Mestrado não publicada, Curso de Mestrado em Psicologia Clínica, Universidade de Brasília. Brasília, D.F.

Santos, B. (1987). Um discurso sobre as ciências. Porto: Afrontamento.

Santos, B. (1989). Introdução a uma ciência pós moderna. São Paulo: Graal White.
White, M. \& Epston, D. (1993). Medios narrativos para fines terapéuticos. Barcelona: Paidós.

Recebido em 17/11/2000

Revisado em 5/12/2000

Aceito em 5/12/2000

Sobre o autor:

Maurício S. Neubern é Doutorando em Psicologia pela Universidade de Brasília - D.F. 